Original Research Paper

\title{
Effect of Climate Change on Sal (Shorea robusta Gaertn. f.) Forest of Kumaun Himalaya
}

\author{
Sanjay Kumar and Neha Chopra \\ Department of Botany, D.S.B. Campus Kumaun University, Nainital-263002, India
}

\section{Article history}

Received: 16-04-2017

Revised: 25-09-2017

Accepted: 26-03-2018

Corresponding Author:

Sanjay Kumar

Department of Botany, D. S. B.

Campus Kumaun University,

Nainital-263002, India

Email: sanjay14.kumar@yahoo.com

\begin{abstract}
Phenophase of three common co-occuring woody plant species that varied in stature (tree Vs shrub) were examined in a sal forest of Kumaun Himalaya. The significance of phonological research lies in the fact that it constitutes a synthetic approach to evaluating plant response to the local environment. Monthly counts of leaves, flowers, fruits and shoot measurement were made on 150 tagged twigs on ten individuals of each species for initiation, completion and duration of different phenological events. In all species, leaves emerged during March-May on the onset of warm and dry summer season. Across all the species, peak leaf area per shoot $\left(9.87-179.14 \mathrm{~cm}^{2}\right)$, leaf extension period (5-7 weeks), shoot extension growth $(9.23-20.11 \mathrm{~cm})$, shoot extension period (24-25 weeks) varied considerably. A significant relationship was found between shoot diameter, shoot length and leaf area extension across all species. Increasing day length/temperature induce flowering in S. robusta and M. paniculata during hot dry summer and the first heavy rain in month of August act as a flowering cue in M. philippinensis during the rainy season.
\end{abstract}

Keywords: Phenology, Leafing, Flowering, Shoot Growth, Shoot Diameter, Litter Fall, Climate Change

\section{Significant Statements}

Changes in the timing of phenological events have significant implications for scientific research. The phenological data used to project future climate scenarios and the projected impacts of such changes on the environment. Therefore, here is a need for further research to be done, using phenological data in computer models to improve understanding of interaction between climate and natural systems to find the best adaptation and mitigation strategies in agriculture, forestry and all other aspects of human life.

\section{Introduction}

Phenological events are very closely related to temperature fluctuations. A minute change in temperature can trigger early/delayed leafing, flowering in plants/trees. The world temperature has risen by $0.6^{\circ} \mathrm{C}$ in the last decade and the related global climate needs to be taken seriously, even though there are uncertainties in temporal and spatial distribution. Global climate change may force variation in timing, duration and synchronization of phenological events in tropical forests (Reich, 1995). Tropical trees are expected to respond variously to changes in rainfall and temperature because they differ widely with respect to adaptations to seasonal drought and cues for bud break of vegetative and flower buds (Singh and Kushwaha, 2005). Several researches also reported signification variation in flowering (advanced or delayed) (Fitter and Fitter, 2002) and fruiting responses (Chapman et al., 2005 ) in tree species as a result of climatic change. The impact of climate change can be better assessed at functional level based on the deciduousness period and at imitation of reproductive phase. The need for functional types has been emphasize to evaluate and predict the nature of vegetation responses to future global change (Box, 1996).

There Precise phenological information with respect to flowering and fruiting, evaluated against leafing and leafless periods, is scarce in tropical deciduous forests in India, which account for approx. $46 \%$ of the forested land in the country. So is the information on onset dates of different phenological events, duration of events and asynchrony in tropical forest trees. In these forests common tree species show a wide range of leafless periods due to differing timings of leaf fall within the annual cycle (Kushwaha and Singh, 
2005). The hypothesis was tested that in tropical deciduous forest trees flowering periodicity has evolved as an adaptation to the annual leafless duration (affecting rate and period of vegetative growth) and the time required for fruit development.

Over the last decades the phenology (Walther et al., 2002) of many plant and animal species has advanced and that these shifts are related to climate change (Hughes, 2000; Parmesan and Yohe, 2003; Root et al., 2003). Now species are showing signification adoptions to changing environment which may be a positive sign or may be a negative sign because they show that this climate impacting living system. However not all species shows sift in phenology (Visser et al., 1998; 2003; Both et al., 2004). Are these the species or population at risk or are these the lucky ones whose environments are not (yet) affected by climate change. Plants and animals show seasonal patterns in their actions because of seasonality in the suitability of their environment: There is often only a limited period in the year when conditions are favourable enough to successfully reproduce or grow. If reproduction or growth takes place outside this window of favourable conditions, there are often large fitness consequences. Ultimately, the activity that is the most demanding for an organism should take place at the time of optimal conditions. What we need to now to evaluate the observed shifts in phenology is how that period of optimal conditions shifts due to climate change. If the phenology of a species is shifting at a different rate from that of the species that make-up its ecological conditions, this will lead to mistiming of its seasonal activities (Visser et al., 2004) or, to use an alternative terminology, to a mismatch in phenology (Stenseth and Mysterud, 2002).

In the Himalayan context there are several tree and shrub species that have short seed viability and coincide their seed maturation with the monsoon showers. Any changes in time of seed maturation of such species can result in severely effects their regeneration and plant biodiversity. In the present study we have tried to compare the shifts in timing of major phenological events in two tree and one shrub species of Shorea robusta Gaertn. f. dominant forest.

\section{Materials and Methods}

\section{Study Area}

The study was conducted in Nainital forest division of Kumaun Himalaya. The study site was located between 1700-1840 m. The studied tree species were Sal $(S$. robusta) with $M$. philippinenisis occurring in the under canopy and for the shrub species $M$. paniculata (Table 1). The soils are residual, originating from slates, phyllites, sandstone and limestone of the Krol series. Sand predominates in the soil (65-85\%), while the silt and clay contents are $10-20 \%$ and $5-10 \%$, respectively. Organic matter ranges between 5.0 and $10.0 \%$ and available $\mathrm{C}$ between 1.8 and $2.5 \%$, the soil $\mathrm{pH}$ ranges between 5 and 6 (Kumar, 2011). The climate is characterized by a summer monsoon and the year has four distinct seasons viz., monsoon (July to September), winter (December to January) and summer (April to midJune). Transition periods between summer and winter and between winter and summer can be recognized as autumn (October to November) and spring (February to March), respectively.

Climatic data for 2008-2009 were obtained from the O/I Agromet Observatory at Pantnagar. The average annual rainfall was $590.87 \mathrm{~mm}$ of, $60 \%$ of which was occur in the rainy season and the mean daily temperature ranged from 6 to $37^{\circ} \mathrm{C}$ (Source: O/I Agromet Observatory, Pantnagar).

\section{Experimental Design}

Phenological records on leaf emergence and leaf drop were made from December 2007 to December 2009 in $S$. robusta dominated forest where trees and shrub of a given species were extensively distributed. The site were visited at a weekly interval during the phenophase was observed in 5-10\% individuals of a species, it was considered to have initiated and the species was considered to be in the phenophase as long as that phenophase was represented by at least $5-10 \%$ individuals. To observed the phenological events 10 average sized mature trees $(\mathrm{dbh}>31.5 \mathrm{~cm})$, having a similar degree of crown development and 10 individuals of shrub were selected within 1 ha permanent plot.

Table 1: Characteristics of woody plant species examined in this study. Data are means $\pm \mathrm{SE}$

\begin{tabular}{|c|c|c|c|c|c|c|}
\hline Speciesa & Family & $\begin{array}{l}\text { Leaf area } \\
\left(\mathrm{cm}^{2}\right)\end{array}$ & $\begin{array}{l}\text { Shoot length } \\
(\mathrm{cm})\end{array}$ & $\begin{array}{l}\text { Shoot diameter } \\
(\mathrm{mm})\end{array}$ & $\begin{array}{l}\text { Leaf } \\
\text { habit }\end{array}$ & Stature \\
\hline Shorea robusta Gaertn.f. & Dipterocarpaceae & $179.14 \pm 1.36$ & $20.11 \pm 1.43$ & $5.04 \pm 0.23$ & Semideciduous & Tree \\
\hline Mallotus philippinensis (Lam.) Muell.-Arg. & Euphorbiaceae & $34.56 \pm 0.79$ & $9.23 \pm 0.70$ & $6.12 \pm 0.25$ & Evergreen & Tree \\
\hline Murraya paniculata (L.) Jack. & Rutaceae & $9.87 \pm 0.53$ & $16.18 \pm 1.78$ & $4.37 \pm 0.26$ & Evergreen & Shrub \\
\hline
\end{tabular}

a nomenclature follows Osmoston (1927) 
In each of the selected individuals, 30 vegetative buds were marked in spring 2008. 15 new shoots (originating from marked buds) were tagged and observed for number of leaves randomly at monthly intervals. In this way it was possible to record the periodical changes in number of leaves precisely. Leaves for each of the tree and shrub species were collected randomly on each of the sampling date (at weekly intervals from bud-break to full leaf expansion and at monthly intervals during the leaf senescence) from the marked twigs. All collected leaves of individual species were sketched on graph paper to measure the leaf area.

To assess the shoot elongation, the distance from the mark to the end of the shoot was measured to the nearest millimeter approximately fortnightly starting from late winter of 2007 for a period of two years. The diameter changes for marked branches were measured by vernier calliper in two directions at right angle to one another to compensate, to extent, for any eccentricity in the shoots. The observations for diameter changes were made each month at approximately the same time of the day on each reading date to reduce effect of thermal expansion and hydration for period of eighteen months from March 2008 to August 2009.

The flowering period of a species was the duration (days) from the initiation of flowering to the completion of flowering amongst its individual. Fruiting period of species was also the duration (days) from the first fruit formation to the last amongst its individual (Kumar et al., 2013).

For studying litter production three plots of $31.5 \times 31.5 \mathrm{~m}^{2}$ were established. The litter was measured by placing five litter traps $\left(1 \times 1 \mathrm{~m}^{2}\right)$ on the forest floor. Each trap was $2 \mathrm{~mm}$ mesh nylon, supported by wooden sides with $25 \mathrm{~cm}$ height. Litter from these traps was collected separately in paper bags and brought in to laboratory where the sample was sorted out in to three main categories viz. (i) leaf litter (ii) wooden litter $(<2$ $\mathrm{cm}$ Diameter) and (iii) miscellaneous litter and dried in shade. Litter sampling study was done during May 2008 to April 2010 (Kumar and Tewari, 2015).

For statistical analysis, the individual tree and shrub were considered to be the experimental units (i.e. replicate) and shoots on each individual were treated as subsamples within the replicate. Shoot growth and shoot diameter increment were analysed using SAS GLM, SAS institute 1985 for completely randomized design.

\section{Results}

\section{Flowering and the Leafing Phenology}

The semi-deciduous species $S$. robusta dropped its leaves during spring season but did not become fully leafless, new leaves began to develop when only a few branches had become naked. In studied species leaf initiation was occurred between mid-March to first half of May. In the first month following the bud-break, the tree species had produced $80-90 \%$ of total number of leaves. Average leafing period was recorded maximum for $S$. robusta (7 weeks) followed by $M$. phillippinensis (6 weeks) and M. paniculata (5 weeks). Additional asynchronous leafing activity in $S$. rubusta was observed in Autumn/Winter season. Variations in leaf initiation time were pronounced in year 2008 and 2009. Leaf initiation was one week earlier in $M$. philippinensis and five weeks in S. robusta in March and May 2009 (Fig. 1A).

\begin{tabular}{|c|c|c|c|c|c|c|c|c|c|c|c|c|}
\hline \multirow[b]{2}{*}{ Species } & Winter & \multicolumn{2}{|c|}{ Spring } & \multicolumn{3}{|c|}{ Summer } & \multicolumn{3}{|c|}{ Monsoon } & \multicolumn{2}{|c|}{ Autumn } & \multirow{2}{*}{$\begin{array}{r}\text { Winter } \\
\text { Dec }\end{array}$} \\
\hline & Jan & Feb & Mar & Apr & May & Jun & Jul & Aug & Sep & Oct & Nov & \\
\hline \multicolumn{13}{|l|}{ S. robusta } \\
\hline & & \#\#\# & \#\#\# & & & & & & & & & \\
\hline & & & & & & & & & & & & \\
\hline \multirow{2}{*}{\multicolumn{13}{|c|}{ M. philippinensis }} \\
\hline & & & & & & & & & & & & \\
\hline & & & & & & & & & & & & \\
\hline & & & & & & & & & & & & \\
\hline & & & & & & & & & & & & \\
\hline \multicolumn{13}{|l|}{ M. paniculata } \\
\hline & & & & 㐩 & & & & & & & & \\
\hline
\end{tabular}




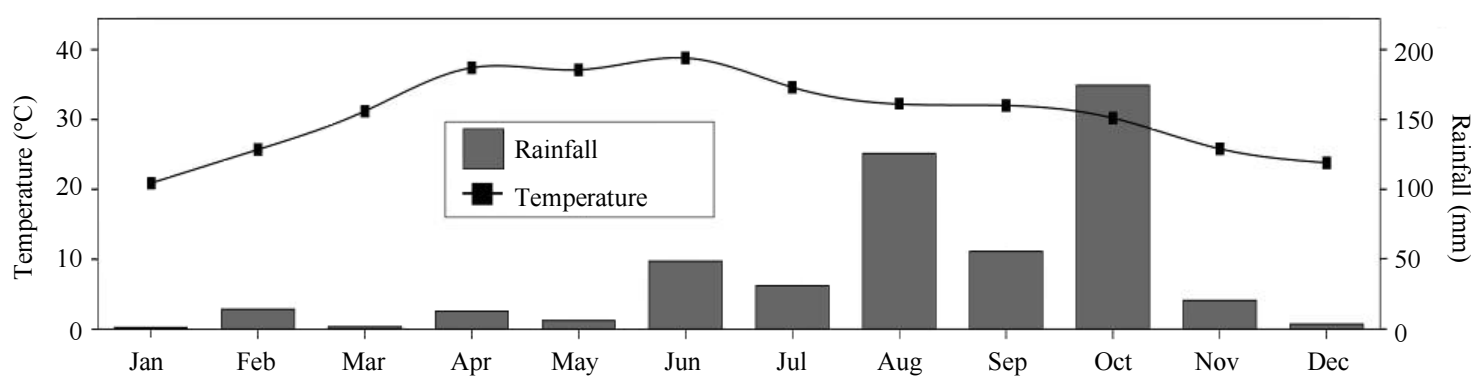

(B)

Fig. 1: Flowering and leafing phenology of S. robusta, M. philippinensis and M. paniculata (A) as observed during climatic conditions (B) as observed in sal forest

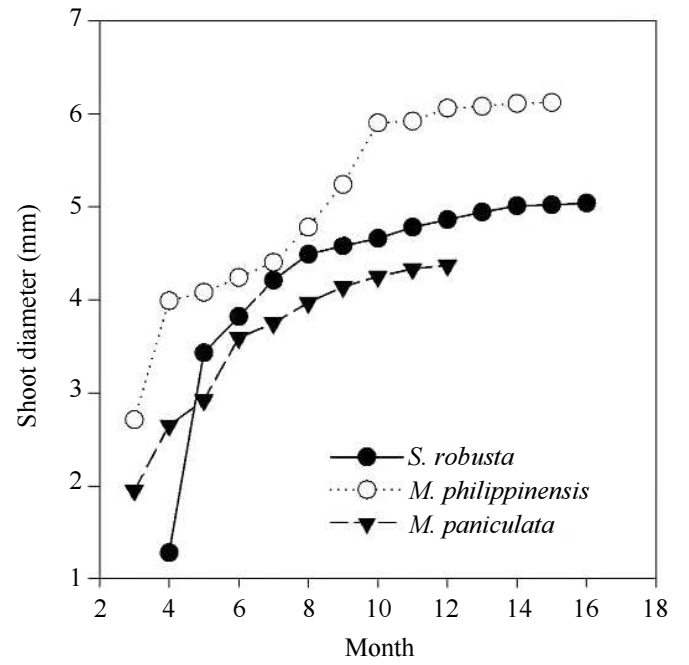

(a)

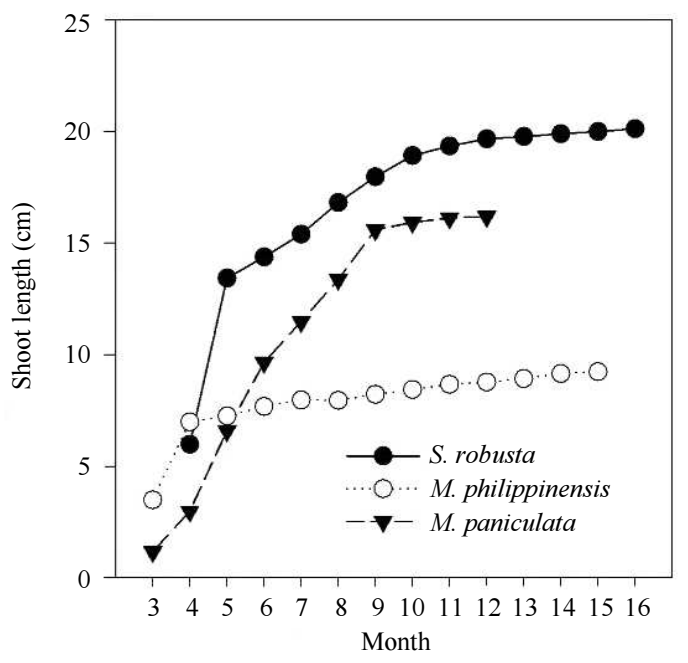

(b)

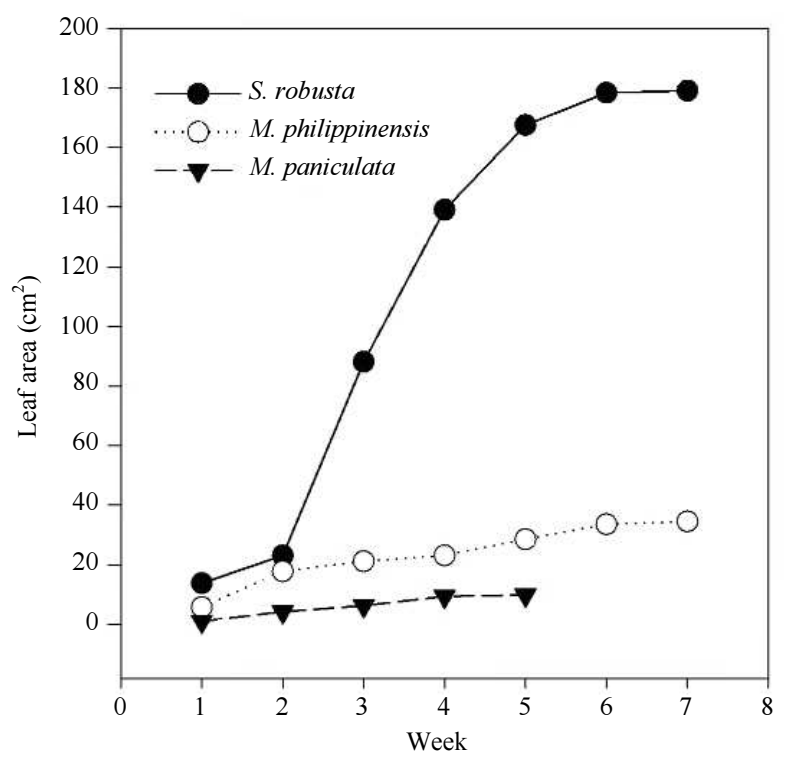

(c)

Fig. 2: Rate and duration of shoot diameter growth (a), shoot length expansion (b) and leaf expansion (c) in $S$. robusta, M. philippinensis and M. paniculata. Bar represent the percent increment and dark circles represent the growth in that particular month 
The peak leaf area was found largest in S. robusta $\left(179.14 \mathrm{~cm}^{2}\right)$ followed by $M$. philippinensis $(34.56$ $\mathrm{cm}^{2}$ ) and M. paniculata $\left(9.87 \mathrm{~cm}^{2}\right)$ (Fig. 2c). The rate of leaf expansion was found maximum for $S$. robusta $\left(3.66 \mathrm{~cm}^{2} \mathrm{day}^{-1}\right)$ followed by M. philippinensis $(0.71$ $\mathrm{cm}^{2}$ day $\left.^{-1}\right)$ and $M$. paniculata $\left(0.28 \mathrm{~cm}^{2}\right.$ day $\left.^{-1}\right)$ (Fig. 2c). Post hoc comparisons indicated that the mean leaf area of $S$. robusta $(\mathrm{M}=112.776, \mathrm{SD}=71.676)$ was significantly different than the $M$. philippinensis $(\mathrm{M}=$ 23.559, $\mathrm{SD}=10.024)$ and $M$. paniculata $(\mathrm{M}=6.204$, $\mathrm{SD}=3.666) . M$. philippinensis did not significantly differ from the $M$. paniculata $(\mathrm{p}<0.785)$. The leaf area $[F(2,16)=10.674, p<0.001]$ was found significant across all the species.

$S$. robusta and $M$. paniculata flowered during February to March month, except M. philippinensis, which flowered in autumn season. No additional bloom was observed during the study period in studied species. Flowering was earlier by one week in $S$. robusta and $M$. philippinensis and delayed by one week in $M$. paniculata in year 2008 compared to 2009. Fruiting occurred during summer season (March to June) in all species.

\section{Shoot Diameter Growth and Shoot Elongation}

Of the total diameter increment, the percentage increment in one month from bud-break ranged between $68.06 \%$ in $S$. robusta to $65.24 \%$ in $M$. paniculata. Compare to trees, in $M$. paniculata the percentage increment in one month was $18.39 \%$. In $S$. robusta, M. philippinensis and M. paniculata, 90\%

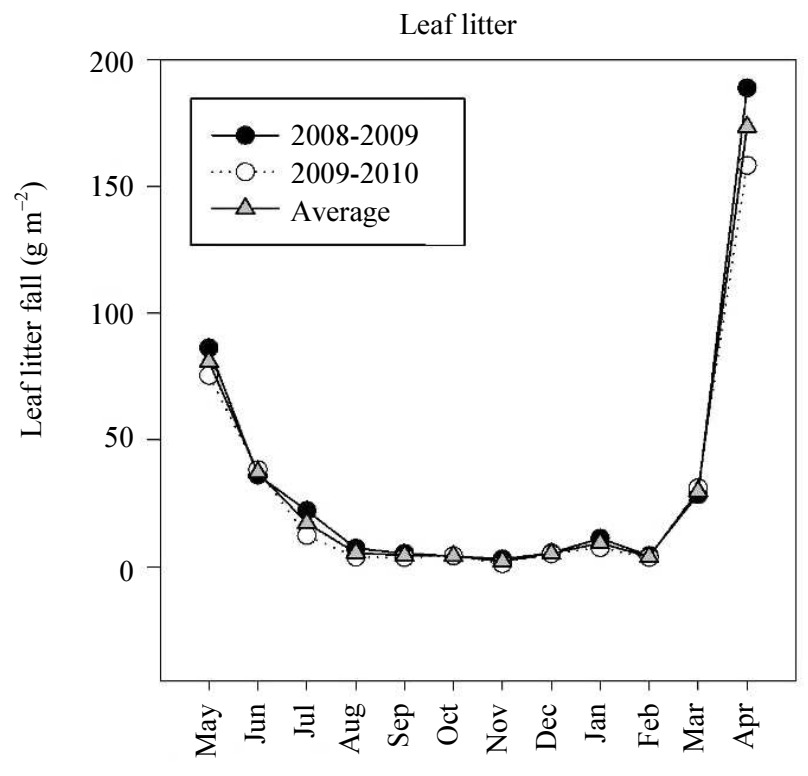

Month shoot elongation was completed by the end of rainy season (i.e., in September). The amount of shoot elongation ranged between $9.23 \mathrm{~cm}$ in $M$. philippinensis, $16.18 \mathrm{~cm}$ in M. paniculata and 20.11 $\mathrm{cm}$ in S. robusta (Fig. 2a). The average percentage of the shoot elongation realized in the first month of bud break was higher for M. philippinensis (75.59\%) followed by $S$. Robusta (66.67\%) and M. paniculata (18.39\%). The shoot diameter ranged between 6.12 $\mathrm{mm}$ in M. philippinensis, $5.04 \mathrm{~mm}$ in S. robusta and $4.37 \mathrm{~mm}$ in $M$. paniculata (Fig. 2b). The shoot elongation of $S$. robusta $\left(\mathrm{n}=11, \mathrm{r}^{2}=0.98, \mathrm{p}<0.01\right), M$. philippinensis $\left(\mathrm{n}=11, \mathrm{r}^{2}=0.82, \mathrm{p}<0.01\right)$ and $M$. paniculata $\left(\mathrm{n}=8, \mathrm{r}^{2}=0.97, \mathrm{p}<0.01\right)$ was significantly related to shoot diameter. Post hoc comparisons using the Tukey HSD test indicated that the mean shoot length of $S$. robusta $(\mathrm{M}=17.045, \mathrm{SD}=4.036)$ was significantly different than the $M$. philippinensis $(\mathrm{M}=7.897, \mathrm{SD}=$ $1.495)$ and $M$. paniculata $(\mathrm{M}=10.899, \mathrm{SD}=5.640) . M$. philippinensis did not significantly differ from the $M$. paniculata $(\mathrm{p}<0.179)$. The mean shoot diameter of $M$. philippinensis $(\mathrm{M}=5.049, \mathrm{SD}=1.101)$ was significantly different than the $M$. paniculata $(\mathrm{M}=3.592, \mathrm{SD}=0.822)$. However, S. robusta $(\mathrm{M}=4.317, \mathrm{SD}=1.036)$ did not significantly differ from the $M$. philippinensis $(\mathrm{p}<0.169)$ and $M$. paniculata $(\mathrm{p}<0.217)$. The shoot length $[\mathrm{F}(2,33)=18.223, \mathrm{p}<0.001]$ and shoot diameter $[\mathrm{F}(2,33)=5.941, \mathrm{p}<0.006]$ was found significant across all the species.

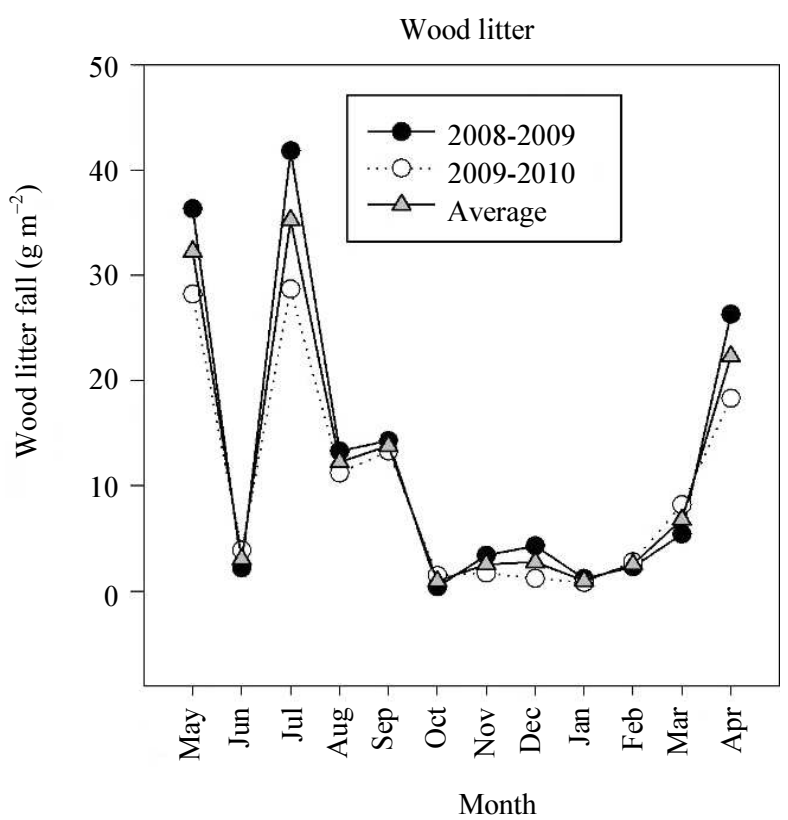



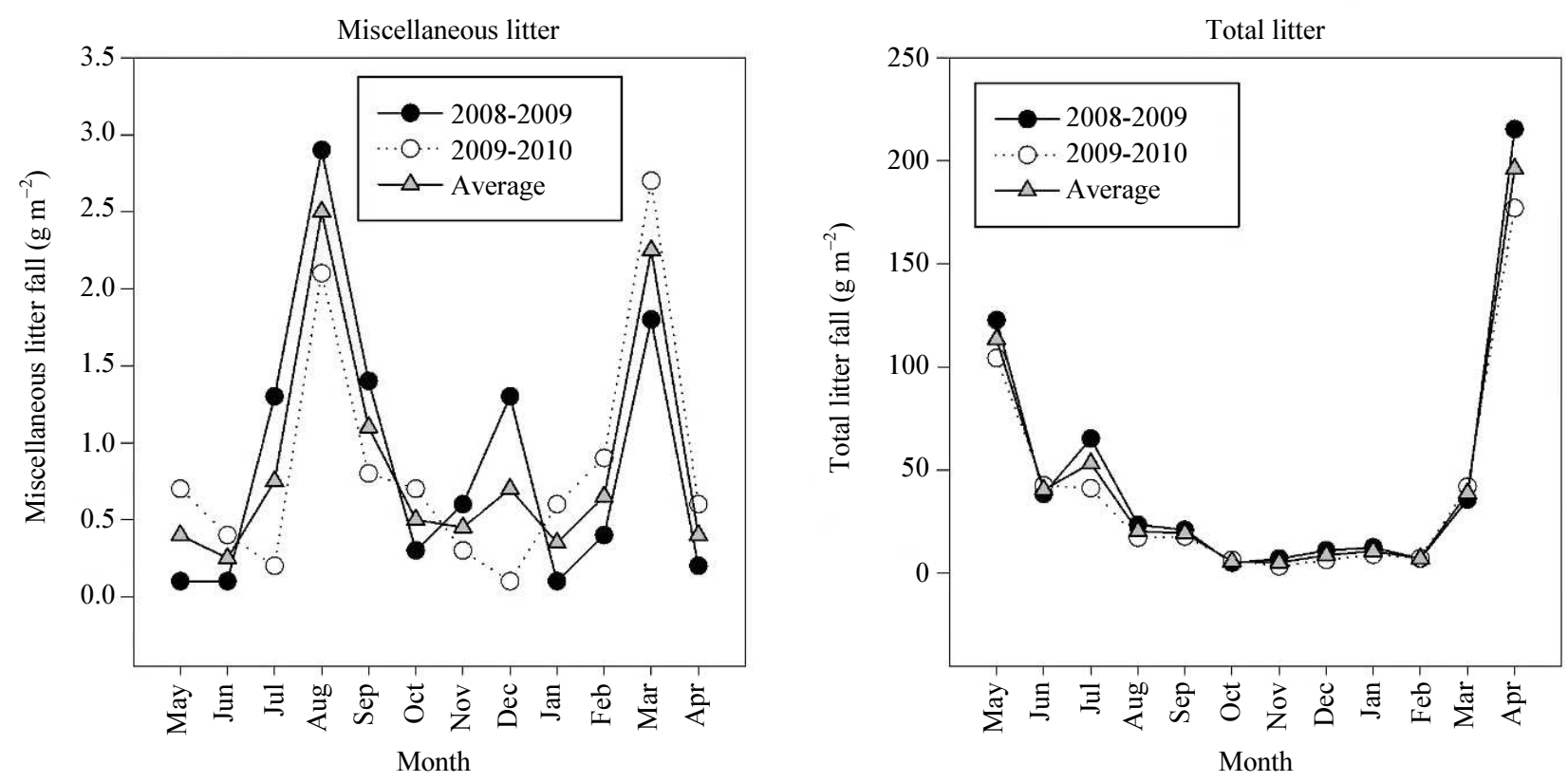

Fig. 3: Monthly leaf, wood, miscellaneous and total litter fall $\left(\mathrm{g} \mathrm{m}^{-2}\right)$ in sal forest

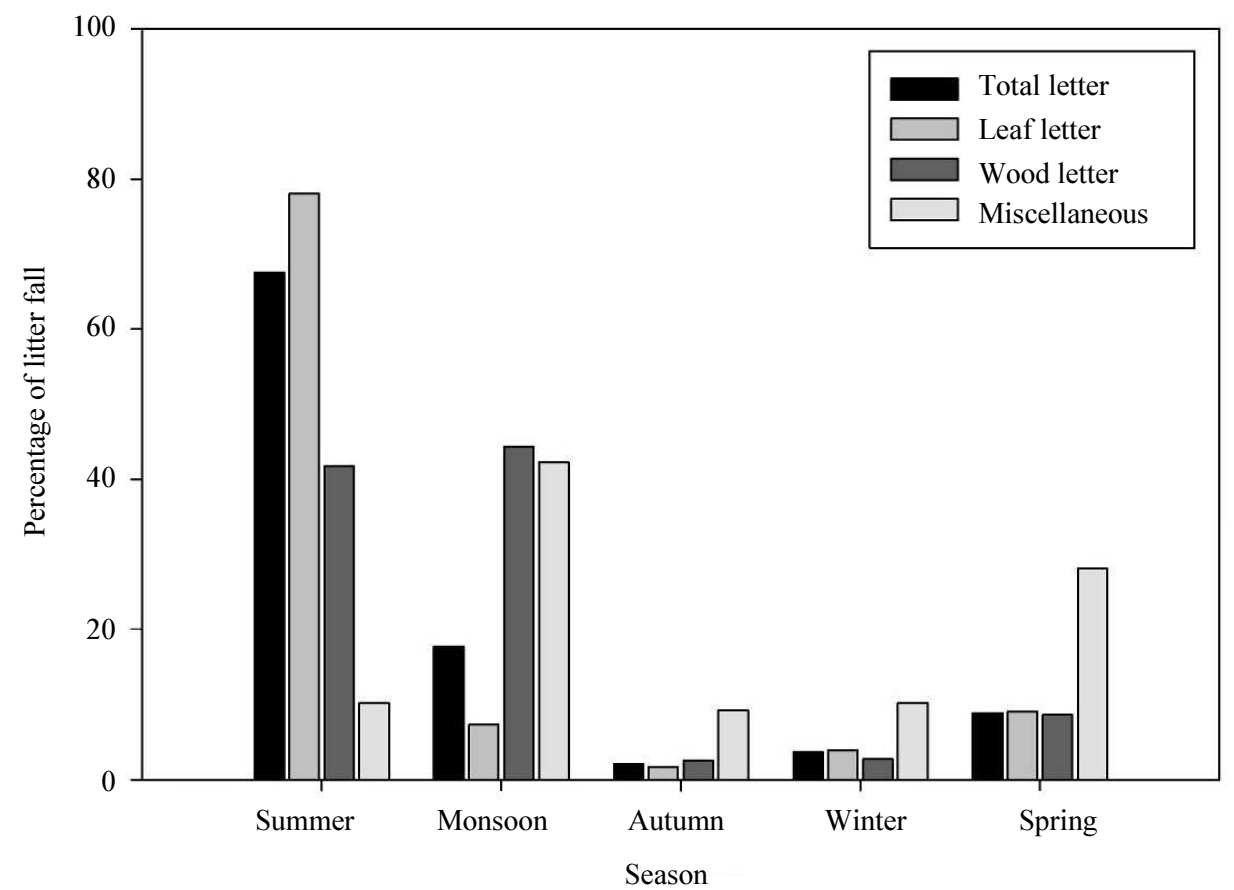

Fig. 4: Contribution of different seasons to annual litter fall in sal forest

\section{Litter Fall}

The leaf fall was greatest in the summer season $(78.04 \%)$, followed by the spring $(9.05 \%)$, monsoon $(7.30 \%)$, winter $(3.91 \%)$ and autumn seasons $(1.72 \%)$. The contribution of leaf litter to total annual litter production was highest during summer months; the leaf litter accounted for $46.44 \%$ (April) to $9.96 \%$
(June) of the respective total monthly fall (Fig. 3). The contribution of wood litter to total annual litter production was highest during monsoon seasons; the wood litter accounted for $25.53 \%$ (July) to $8.87 \%$ (August) of the respective total monthly fall. The wood fall was greatest in the monsoon season $(44.40 \%)$, followed by the summer $(41.72 \%)$, spring $(8.62 \%)$, winter $(2.71 \%)$ and autumn seasons $(2.54 \%)$. 
Table 2: Coefficients of correlation, slope and intercepts of linear regressions relating monthly litter fall ( $\mathrm{g} \mathrm{m}$ 2) to mean monthly temperature $\left({ }^{\circ} \mathrm{C}\right)$

\begin{tabular}{llll}
\hline Litter fall & Slope & Intercept & $\mathrm{r}$ \\
\hline Leaf litter & 7.852 & -201.286 & $0.715^{* * *}$ \\
Wood litter & 1.692 & -38.589 & $0.636^{* * *}$ \\
Miscellaneous litter & 0.02 & 0.28 & 0.71 \\
Total litter & 9.601 & -240.992 & $0.768^{* * *}$ \\
\hline
\end{tabular}

$* * *=$ significant at $\mathrm{p}<0.01$.

The contribution of miscellaneous litter to total annual litter production was highest during monsoon seasons; the miscellaneous litter accounted for $24.27 \%$ (August) to $7.28 \%$ (July) of the respective total monthly fall. The miscellaneous fall was greatest in the monsoon season $(42.23 \%)$, followed by the spring $(28.15 \%)$, winter $(10.20 \%)$, summer $(10.19 \%)$ and autumn season (9.22\%) (Fig. 4). The relationship between the litter fall to mean monthly temperature was found significant (Table 2). The contribution of leaf fall to total annual litter in respective month was highest during summer months; the leaf litter accounted for $88.43 \%$ (April) to $71.23 \%$ (May). The wood fall contribution was highest during monsoon months; the wood litter accounted for $71.32 \%$ (September) to $66.20 \%$ (July) and highest during autumn by Miscellaneous litter. The miscellaneous litter accounted for $6.67 \%$ (October) to $8.74 \%$ (November).

\section{Discussion}

Very few studies have examined the possible functional significance of an interrelationship between leafing and flowering/fruiting phenophases in tropical trees (van Schaik et al., 1993). Occurrence of leaf flushing (vegetative phase) and flowering (reproductive phase) requires the availability of substantial amounts of resources within the trees. For instance, flower production and maintenance requires considerable expense of energy to form non photosynthetic tissues and nectar (Ashman and Schoen, 1997). Besides, the time lag between these two events reflects partitioning of resource use for vegetative and reproductive functions. Various physiologically active sites or sinks (e.g., leaf buds and leaves, flower buds and flowers and fruit) may compete for water, nutrients and metabolites (Lieberman, 1982) and such internal competition may lead to the partitioning in time of plant functions like leafing and flowering. While the two survival adaptations (leafless period and flowering time) are linked with capacity adaptation (e.g., resource-use rate), the duration of deciduousness and time lag between onset of leafing and flowering help trees in making maximum use of available resources for growth and reproduction. Seasonally dry forests are characterized by sudden increase (after rain onset) and slow reduction (after rain cessation) in resource availability and, under such conditions, optimization of vegetative growth is crucial for tree survival and reproduction. It is suggested that flowering time and time lag between the onset of leafing and flowering affect the degree of separation of resource use for vegetative and reproductive events within trees. Variation in flowering time in different species may be related to resource-use rate during vegetative growth (which depends on the duration of deciduousness) and the time required for fruit development. In the deciduous tree species in the present study, the longer the leafless duration, the more delayed (greater time lag) is the initiation of flowering relative to leaf flushing. The leafless period is an adaptation to avoid water stress and water stress affects flowering time in tropical forest trees (Bullock, 1995). Increase in leafless period in deciduous species results in reduction in the vegetative growth period and drought stress is not only reflected in terms of leafless period, but is also evident from the greater seasonal separation between the two phases.

Earlier flowering implies earlier activity in other process (leaf expansion, root growth, nutrient uptake) that are important for niche differentiation among coexisting species (Veresoglou and Fitter, 1984; McKane et al., 1990) and so will alter competitive interactions between species. Large changes in flowering date will therefore disrupt ecosystem structure. Flowering and fruiting in tropical deciduous forest trees typically occur throughout the year on one species or another. Synchronization of flowering with a particular season of the annual cycle by many species appears to be under the control of prevailing climatic conditions of that season. The detection of several flowering types in Indian tropical trees revealed that a variety of strategies have evolved to ensure survival and reproduction under a monsoonic bioclimate (Singh and Kushwaha, 2006). Many species have been reported to regularly flower synchronously after the spring equinox during March-June (Van Devender et al., 2000; Felger et al., 2001). Increasing day length/temperature may induce flowering in S. robusta and M. paniculata during hot dry summer and the first heavy rain in month of August may act as a flowering cue in $M$. philippinensis during the rainy season.

In present study, the months of leafing were much warmer than 1986 (the mean maximum temperature in March-April were 31.2 and $37.1^{\circ} \mathrm{C}$ respectively compared to 22 and $26^{\circ} \mathrm{C}$ in 1986) (Fig. 5). In present 
study $S$. robusta showed leafing earlier due to the early rise in temperature of March in comparison to 1986 where it was observed in April (Negi, 1989). The predominant role of leaf shedding in triggering flowering as a result of stem rehydration is indicated in winterflowering, leaf-exchanging $S$. robusta and dry season flowering in $M$. panicualata. Autumn flowering occurs during early dry season at a time when carbohydrate reserves are in plenty and climate conditions are favourable for reproduction before depletion of soil water reserves. Declining day length may induce synchronous development of flowers in autumn-flowering (September-November) species ( $M$. philippinensis). Flower development on foliated shoots after the autumn equinox indicates flower induction by declining day length (Rivera and Borchert, 2001). Different flowering types are related to varying durations of fruiting phenophase (summerflowering species, approx. 5.5 weeks in S. robusta and M. philippinensis, rainy flowering species, approx. 4.5 weeks in $M$. paniculata). In the present study, all flowering types complete the fruiting phenophase during late dry season before the onset of the succeeding rainy season, ensuring that some, if not all, seeds are available for germination when the soil is sufficiently moist. Singh and Singh (1984) reported the species producing peak standing crop for mature fruits in summer season lack seed dormancy and their seeds germinate rapidly within a short viability period, while those with post-rainy season standing crop of mature fruits require ageing/winter chilling for seed germination. In the latter species the seed germination is distributed over long period extending upto warm and dry season. In the former group of the species seed germination is synchronized with the rainy season (which immediately follows the summer season). It is of the competitive advantage for the species to germinate rapidly, without a period of dormancy in the condition of adequate soil moisture. In $S$. roubsta seed viability lasts for only about two weeks (Rao and Singh, 1985). Fruit maturation and suitable conditions for dispersal are closely synchronized in tropical dry forests because of the pronounced differences of biotic and abiotic conditions between dry and rainy seasons (Griz and Machado, 2001). It is suggested that the duration of fruiting phenophase depends, at least to some extent, on the time of flowering and the leafless period during the annual cycle.

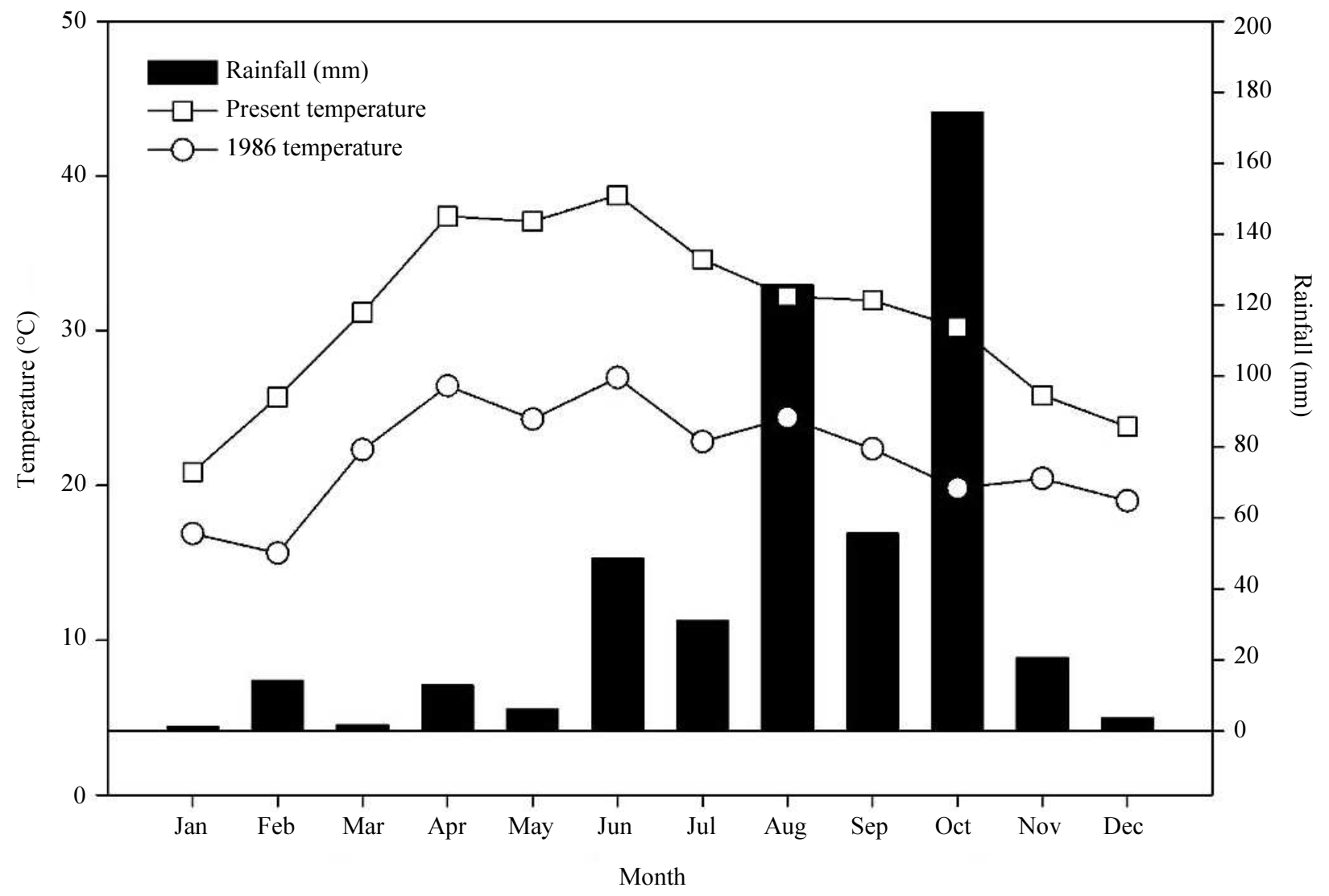

Fig. 5: Comparison of present and past climatic condition of study site 


\section{Conclusion}

Based on the finding on phenology it may be stated that, the enough moisture content and temperature during favorable growth season are key determinants for growth and development in $S$. robusta, $M$. philippinensis and M. paniculata. Detailed studies are required on their water relations, particularly in reference to adaptive features of mature leaves of evergreen species to withstand the post-monsoon drought and of young leaves of both deciduous and evergreen species to withstand pre-monsoon drought.

\section{Author's Contributions}

Sanjay Kumar: Participated in all experiments, coordinated the data-analysis and contributed to the writing of the manuscript.

Neha Chopra: Designed the research plan and organized the study.

\section{Conflict of Interest}

Authors declare that they have no conflict of interest

\section{References}

Ashman, T.L. and D.J. Schoen, 1997. The cost of floral longevity in Clarkia tembloriensis: an experimental investigation. Evolut. Ecol., 11: 289-300. DOI: $10.1023 / \mathrm{A}: 1018416403530$

Both, C., A.V. Artemyev, B. Blaauw, R.J. Cowie and A.J. Dekhuijzen et al., 2004. Large-scale geographical variation confirms that climate change causes birds to lay earlier. Proc. R. Soc. B, 271: 1657-1662. DOI: 10.1098/rspb.2004.2770

Box, E.O., 1996. Plant functional types and climate at the global scale. J. Veget. Sci., 7: 309-320. DOI: $10.2307 / 3236274$

Bullock, S.H., 1995. Plant Reproduction in Neotropical Dry Forests. In: Seasonally Dry Tropical Forests, Bullock, S.H., H.A. Mooney and E. Medina (Eds.), Cambridge University Press, Cambridge, pp: 277-303.

Chapman, C.A., L.J. Chapman, T.T. Struhsaker, A.E. Zanne and C.J. Clark et al., 2005. A long-term evaluation of fruiting phenology: Importance of climate change. J. Tropical Ecol., 21: 31-45. DOI: $10.1017 / \mathrm{S} 0266467404001993$

Felger, R.S., M.B. Johnson and M.F. Wilson, 2001. The trees of Sonora, Mexico. 1st Edn., Oxford University Press, Oxford, ISBN-10: 0195128915, pp: 400 .

Fitter, A.H. and R.S.R. Fitter, 2002. Rapid changes in flowering time in British plants. Science, 296: 1689-1692. DOI: 10.1126/science. 1071617
Griz, L.M.S. and I.C.S. Machado, 2001. Fruiting phenology and seed dispersal syndromes in caatinga, a tropical dry forest in the northeast of Brazil. J. Tropical Ecol., 17: 303-321. DOI: $10.1017 / \mathrm{S} 0266467401001201$

Hughes, L., 2000. Biological consequences of global warming: Is the signal already apparent? Trends Ecol. Evol., 15: 56-61. DOI: $10.1016 / \mathrm{S} 0169-5347(99) 01764-4$

Kumar, S. and L.M. Tewari, 2015. Pattern of litter fall in Pinus roxburghii Sarg. forest in Kumaun Himalaya, India. Ind. J. Ecol., 42: 219-223.

Kumar, S., 2011. Studies on phenology and seedling dynamics of major tree and shrub species along an altitudinal gradient in Kumaun Himalaya. Kumaun University, Nainital.

Kumar, S., L.M. Tewari and A. Tewari, 2013. Leaf demography of some evergreen and deciduous tree and shrub species of Kumaun Himalaya, India. Ecosyst. Ecography, 3: 127-127. DOI: $10.4172 / 2157-7625.1000127$

Kushwaha, C.P. and K.P. Singh, 2005. Diversity of leaf phenology in a tropical deciduous forest in India. J. Tropical Ecol., 21: 47-56. DOI: $10.1017 / \mathrm{S} 0266467404002032$

Lieberman, D., 1982. Seasonality and phenology in a dry tropical forest in Ghana. Ecology, 70: 791-806. DOI: $10.2307 / 2260105$

McKane, R.B., D.F. Grigal and M.P. Russelle, 1990. Spatiotemporal differences in $15 \mathrm{~N}$ uptake and the organization of an old-field plant community. Ecology, 71: 1126-1132. DOI: 10.2307/1937380

Negi, G.C.S., 1989. Phenology and Nutrient dynamics of tree leaves in Kumaun Himalaya. Kumaun University, Nainital.

Osmoston, A.E., 1927. A forest flora of Kumaun. Allahabad.

Parmesan, C. and G. Yohe, 2003. A globally coherent fingerprint of climate change impacts across natural systems. Nature, 421: 37-42.

DOI: 10.1038 /nature 01286

Rao, P.B. and S.P. Singh, 1985. Population dynamics of a foot-hill sal (Shorea robusta Gaertn.f.) forest in kumaun Himalaya. Ecol. Plant., 6: 161-166.

Reich, P.B., 1995. Phenology of tropical forests: Patterns, causes and consequences. Canad. J. Botany, 73: 164-174. DOI: 10.1139/b95-020

Rivera, G. and R. Borchert, 2001. Induction of flowering in tropical trees by a $30-\mathrm{min}$ reduction in photoperiod: Evidence from field observations and herbarium specimens. Tree Physiol., 21: 201-212. DOI: $10.1093 /$ treephys/21.4.201

Root, T.L., J.T. Price, K.R. Hall, S.H. Schneider and C. Rosenzweig et al., 2003. Fingerprints of global warming on wild animals and plants. Nature, 421: 57-60. DOI: 10.1038/nature01333 
Singh, J.S. and S.P. Singh, 1984. An integrated ecological study of eastern Kumaun Himalaya with emphasis on natural resources. Vol.2. Site specific studies. Final report (HCS/DST/187/76). Kumaun University.

Singh, K.P. and C.P. Kushwaha, 2005. Emerging paradigms of tree phenology in dry tropics. Curr. Sci., 89: 964-975.

Singh, K.P. and C.P. Kushwaha, 2006. Diversity of flowering and fruiting phenology of trees in a tropical deciduous forest in India. Annals Botany, 97: 265-276. DOI: $10.1093 / \mathrm{aob} / \mathrm{mcj} 028$

Stenseth, N.C. and A. Mysterud, 2002. Climate, changing phenology and other life history traits: nonlinearity and match-mismatch to the environment. Proc. Natl Acad. Sci. USA, 99: 13379-13381.

DOI: $10.1073 /$ pnas.212519399

Van Devender, T., A.C. Sanders, R.K. Wilson and S.A. Meyer, 2000. Vegetation, Flora and Seasons of the Rio Cuchujaqui, a Tropical Deciduous Forest Near Alamos, Sonora. In: The Tropical Deciduous Forest of Alamos, Robichaux, R.H. and D.A. Yetman (Eds.) The University of Arizona Press, Tucson, AZ, pp: 36-101.

van Schaik, C.P., J.W. Terborgh and S.J. Wright, 1993. The phenology of tropical forests: Adaptive significance and consequences for primary consumers. Annual Rev. Ecol. Systemat., 24: 353-377.

DOI: 10.1146/annurev.es.24.110193.002033
Veresoglou, D.S. and A.H. Fitter, 1984. Spatial and temporal patterns of growth and nutrient uptake of five co- existing grasses. J. Ecol., 72: 259-272. DOI: $10.2307 / 2260018$

Visser, M.E., A.J. van Noordwijk, J.M. Tinbergen and C.M. Lessells, 1998. Warmer springs lead to mistimed reproduction in great tits (Parus major). Proc. R. Soc. B, 265: 1867-1870. DOI: $10.1098 /$ rspb.1998.0514

Visser, M.E., C. Both and M.M. Lambrechts, 2004. Global climate change leads to mistimed avian reproduction. Adv. Ecol. Res., 35: 89-110. DOI: $10.1016 / \mathrm{S} 0065-2504(04) 35005-1$

Visser, M.E., F. Adriaensen, J.H. van Balen, J. Blondel and A.A. Dhondt et al., 2003. Variable responses to large-scale climate change in European Parus populations. Proc. R. Soc. B, 270: 367-372. DOI: $10.1098 / \mathrm{rspb} .2002 .2244$

Walther, G.R., E. Post, P. Convey, A. Menzel and C. Parmesan et al., 2002. Ecological responses to recent climate change. Nature, 416: 389-395. DOI: $10.1038 / 416389$ a 